12 Rankin J. Cerebral vascular accidents in patients over the age of 60. II. Prognosis. Scott Med J 1957;2(5):200-215

13 Kothari RU, Brott T, Broderick JP, et al. The ABCs of measuring intracerebral hemorrhage volumes. Stroke 1996;27(8): 1304-1305

14 Pisters R, Lane DA, Nieuwlaat R, de Vos CB, Crijns HJ, Lip GY. A novel user-friendly score (HAS-BLED) to assess 1-year risk of major bleeding in patients with atrial fibrillation: the Euro Heart Survey. Chest 2010;138(5):1093-1100

15 Kuramatsu JB, Gerner ST, Schellinger PD, et al. Anticoagulant reversal, blood pressure levels, and anticoagulant resumption in patients with anticoagulation-related intracerebral hemorrhage. JAMA 2015;313(8):824-836
16 Vermeer SE, Algra A, Franke CL, Koudstaal PJ, Rinkel GJ. Long-term prognosis after recovery from primary intracerebral hemorrhage. Neurology 2002;59(2):205-209

17 Izumihara A, Suzuki M, Ishihara T. Recurrence and extension of lobar hemorrhage related to cerebral amyloid angiopathy: multivariate analysis of clinical risk factors. Surg Neurol 2005;64(2):160-164

18 Hanger HC, Wilkinson TJ, Fayez-Iskander N, Sainsbury R. The risk of recurrent stroke after intracerebral haemorrhage. J Neurol Neurosurg Psychiatry 2007;78(8):836-840

19 Biffi A, Halpin A, Towfighi A, et al. Aspirin and recurrent intracerebral hemorrhage in cerebral amyloid angiopathy. Neurology 2010;75(8):693-698

\title{
Endovascular Coiling in a Patient with Chronic Kidney Disease-A Challenge for Anesthesiologist
}

\author{
Navneh Samagh ${ }^{1}$ Nidhi Singh ${ }^{2}$ Kiran Jangra ${ }^{2}$ Ajay Kumar ${ }^{3}$ \\ ${ }^{1}$ Department of Anesthesiology, All India Institute of Medical \\ Sciences, Bathinda, Punjab, India \\ ${ }^{2}$ Department of Anaesthesia and Intensive care, Postgraduate \\ Institute of Medical Education and Research, Chandigarh, India \\ Address for correspondence Kiran Jangra, DM, Department \\ of Anaesthesia and Intensive Care, 4th Floor, Nehru Hospital, \\ Postgraduate Institute of Medical Education and Research, \\ Chandigarh 160012, India (e-mail: drkiransharma0117@gmail.com).
}

${ }^{3}$ Department of Radiodiagnosis, Postgraduate Institute of Medical Education and Research, Chandigarh, India

J Neuroanaesthesiol Crit Care 2021;8:207-210.
Abstract
Keywords
- autosomal dominant polycystic kidney disease
- contrast induced nephropathy
- end-stage renal disease
- endovascular coiling
- iso-osmolar contrast medium

A 41-year-old male patient, a known case of autosomal dominant polycystic kidney disease (ADPCKD), presented to our institute with right middle cerebral artery aneurysm for which balloon-assisted endovascular coiling was planned. The major comorbidities were hypertension and end-stage renal disease (ESRD) on hemodialysis, twice weekly. Endovascular coiling was performed under general anesthesia, and special precautions were taken with regard to monitoring, fluid management, use of heparin, and contrast agent. The intraoperative and postoperative course was uneventful, and the patient was discharged after 7 days. In this report, various perioperative challenges of patients with chronic renal failure during coiling are discussed along with the measures to prevent the occurrence of contrast-induced nephropathy. published online

June 1, 2020
DOI https://doi.org/

$10.1055 / \mathrm{s}-0040-1712081$

ISSN 2348-0548. (c) 2020. Indian Society of Neuroanaesthesiology and Critical Care. This is an open access article published by Thieme under the terms of the Creative Commons Attribution-NonDerivative-NonCommercial-License, permitting copying and reproduction so long as the original work is given appropriate credit. Contents may not be used for commercial purposes, or adapted, remixed, transformed or built upon. (https://creativecommons.org/licenses/by-nc-nd/4.0/).

Thieme Medical and Scientific Publishers Pvt. Ltd. A-12, 2nd Floor, Sector 2, Noida-201301 UP, India 


\section{Introduction}

The patients with autosomal dominant polycystic kidney disease (ADPCKD) has a very high incidence of having intracranial aneurysms. ${ }^{1}$ These patients may develop chronic renal failure and also need regular dialysis. Such patients pose a great challenge for neuroradiologists as they are prone to the contrast-induced complications as well as fluid and electrolyte imbalance during coiling. Here, we present a case of ADPCKD with end-stage renal disease (ESRD) who presented with coiling of a ruptured cerebral aneurysm.

\section{Case Report}

A 41-year-old male patient, known case of ADPCKD with hypertension and ESRD on biweekly hemodialysis, presented with sudden onset of severe headache and vomiting. His Glasgow coma scale (GCS) score was 15 . Noncontrast computed tomography (CT) scan revealed hyperdensities in the right sylvian fissure suggestive of the Fisher grade-1 subarachnoid hemorrhage (SAH). CT angiography revealed a narrow neck right middle cerebral artery aneurysm measuring $3.5 \times 2.5 \mathrm{~mm}$ with stalk measuring $1.5 \mathrm{~mm}$. The patient was Hunt and Hess grade-1 and World Federation of Neurological Surgeons (WFNS) grade 1. A balloon-assisted coiling was planned. The patient was started on nimodipine $60 \mathrm{mg}$ every 4 hours and injection levetiracetam $500 \mathrm{mg}$ IV bd. Preanesthetic checkup was done and written informed consent was taken. Heparin-free hemodialysis was done through left arteriovenous fistula 12 hours before the procedure, and $1.5 \mathrm{~L}$ of ultrafiltrate was removed. Postdialysis investigations were urea-50mg/dl, creatinine-7.2, serum sodium-139 mEq/L, serum potassium- $4.2 \mathrm{mEq} / \mathrm{L}$, chloride-97 $\mathrm{mEq} / \mathrm{L}$, prothrombin index-93\%, and international normalization ratio-1.05. His hemogram, arterial blood gases, and liver function tests were normal. The eGFR of the patient was $9 \mathrm{ml} / \mathrm{min} / 1.73 \mathrm{~m}^{2}$. ECG showed normal sinus rhythm with left ventricular hypertrophy (LVH). Echocardiography revealed normal left ventricular systolic function, ejection fraction of $55 \%$, mild concentric LVH, and left ventricular diastolic dysfunction grade 1. Intraoperatively, standard monitors were attached, and the arterial line was inserted in the left radial artery for invasive arterial blood pressure monitoring and blood sampling. The patient was induced with injection fentanyl 100 micrograms, injection propofol $60 \mathrm{mg}$, and injection atracurium $40 \mathrm{mg}$. The trachea was intubated with a cuffed endotracheal tube of size $8.5 \mathrm{~mm}$ internal diameter. Under ultrasound guidance, the right internal jugular vein was cannulated for intraoperative trend monitoring. The baseline central venous pressure (CVP) was measured as $8 \mathrm{~mm}$ of $\mathrm{Hg}$ and was kept $<15 \mathrm{~mm}$ of $\mathrm{Hg}$ during the procedure. The patient was maintained on $\mathrm{O}_{2}, \mathrm{~N}_{2} \mathrm{O}$ (50:50) mixture with propofol to achieve a bispectral index (BIS) between 40 to 60 . The patient was heparinized using 0.8 to $1.4 \mathrm{~mL}$ of 1 in $5000 \mathrm{IU}$ of heparin during the procedure. The flush fluid was prepared by adding $1000 \mathrm{IU}$ of heparin in addition to $500 \mathrm{~mL}$ of $0.9 \%$ normal saline.

Total fluid intake was $900 \mathrm{~mL}$ (flush fluid was used by the neuroradiologist and IV fluid was used by the anesthesiologist), and urine output was $150 \mathrm{~mL}$. We limited the use of IV fluid to a total of $100 \mathrm{~mL}$. Episodes of intraoperative hypotension were managed by using phenylephrine boluses (0.5$1 \mu \mathrm{g} / \mathrm{kg}$ ). The duration of coiling was 2 hours, and the duration of anesthesia was 3 hours. A total of $40 \mathrm{~mL}$ of iso-osmolar iodinated contrast was used in three runs. The patient was extubated at the end of the procedure after the fulfillment of the extubation criteria. Patients had an uneventful postoperative course and were discharged after 7 days. On postoperative day 1 , his serum urea $46 \mathrm{mg} / \mathrm{dl}$ and creatinine was 7.4. The frequency of dialysis was the same as preoperatively after 3 months postprocedure.

\section{Discussion}

SAH affects the functioning of multiple body systems, including cardiovascular, respiratory, renal, coagulation, endocrine, and gastrointestinal systems. These effects may exaggerate the organ dysfunctions in patients with chronic kidney disease (CKD). - Table 1 summarizes the systemic impacts of $\mathrm{SAH}$ and $\mathrm{CKD} .^{2-7} \mathrm{~A}$ thorough evaluation of all the body systems is recommended in these patients. ECG and echocardiographic abnormalities due to CKD are difficult to differentiate from those due to SAH. SAH-induced changes are reversible to some extent in the early postoperative period, while CKDinduced changes may worsen with time. Renal function parameters and serum electrolytes should be evaluated. For patients on renal replacement therapy, a thorough history, including daily fluid intake, urine output, and type and frequency of renal replacement therapy must be noted. Dialysis should be scheduled, preferably 12 to 24 hours before the procedure, to achieve postdialysis homeostasis. ${ }^{4}$ Their dialysis prescription should be altered to minimize changes in serum osmolality and fall in blood pressure.

Intraoperative monitoring in these patients should comprise of ECG, noninvasive blood pressure (NIBP), $\mathrm{SpO}_{2}$, invasive arterial blood pressure (IABP), CVP monitoring, hourly urine output, and temperature monitoring. Serial arterial blood gas (ABG) analysis must be done for earlier detection of electrolyte abnormalities and acid-base disorders. As both CKD and SAH can affect the coagulation system, systemic anticoagulants should be avoided, and if it is necessary, then activated clotting time (ACT) should be monitored periodically during the procedure. Careful monitoring of rebleeding should be done in a situation where anticoagulation is used.

The presence of CKD is one of the most important predictors for the occurrence of contrast-induced nephropathy (CIN) and increases the risk by more than 20 times. ${ }^{5}$ Risk stratification is done based on the estimated glomerular filtration rate (eGFR).The risk of CIN is high in patients where eGFR is 40 to $45 \mathrm{~mL} / \mathrm{min}$, and special precautions should be taken in these patients to reduce this risk. ${ }^{6}$ Fluid loading is an important measure to reduce the incidence as well as the severity of CIN. Hydration prior to the contrast administration should be restricted to minimal fluid in the patients who are on maintenance hemodialysis with minimal urine output. ${ }^{7}$ Both the maintenance fluids and flush saline should be restricted.

Another important precaution to be instituted is the type of contrast media. The ionic and high-osmolar media should 
Table 1 Systemic changes in patients with chronic kidney disease and subarachnoid hemmorhage $\mathrm{e}^{2-7}$

\begin{tabular}{|c|c|c|}
\hline & CKD & SAH \\
\hline Cardiovascular system & $\begin{array}{l}\text { - Hypertension } \\
\text { - Volume overload } \\
\text { - Left ventricular hypertrophy } \\
\circ \text { Arrhythmias } \\
\circ \text { Myocardial infarction } \\
\circ \text { Cardiac failure }\end{array}$ & $\begin{array}{l}\circ \text { Hypertension } \\
\circ \text { Arrhythmias } \\
\circ \text { Pulmonary hypertension } \\
\circ \text { Myocardial dysfunction } \\
\circ \text { Elevation of cTnl } \\
\circ \text { Neurogenic stunned myocardium }\end{array}$ \\
\hline Respiratory system & $\begin{array}{l}\text { - Frequent respiratory infections } \\
\text { - Pulmonary edema } \\
\text { - Pleural effusion }\end{array}$ & $\begin{array}{ll}\circ & \text { Respiratory dysfunction } \\
\circ & \text { Increased risk of aspiration } \\
\circ & \text { Neurogenic pulmonary edema }\end{array}$ \\
\hline $\begin{array}{l}\text { Renal system and electro- } \\
\text { lyte abnormalities }\end{array}$ & $\begin{array}{l}\circ \text { Impaired ability to concentrate and dilute } \\
\text { urine } \\
\circ \text { Fluid excess: } \\
\circ \text { Hyperchloremic metabolic acidosis } \\
\circ \text { Volume overload } \\
\circ \text { Fluid restriction: } \\
\circ \text { Hypertonicity } \\
\circ \text { Hypernatremia } \\
\circ \text { Hyperkalemia }\end{array}$ & $\begin{array}{l}\circ \text { Hyponatremia: } \\
\circ \text { SIADH } \\
\circ \text { Cerebral sodium wasting } \\
\circ \text { Hypernatremia } \\
\circ \text { Hypokalemia } \\
\circ \text { Hypomagnesemia } \\
\circ \text { Worsening of existing renal disease }\end{array}$ \\
\hline Coagulation system & $\begin{array}{l}\text { - Uremic thrombocytopathy } \\
\text { - Defective von Willebrand factor-platelet gly- } \\
\text { coprotein Ilb-Illa receptor interactions } \\
\text { - Prolonged bleeding time } \\
\text { - Reduced platelet ADP content, and reduced } \\
\text { thromboxane A2 } \\
\text { - Reduced brinolysis } \\
\circ \text { Vascular access thrombosis }\end{array}$ & $\begin{array}{l}\text { - High incidence of coagulative and fibrinolytic } \\
\text { disorders } \\
\text { - High level of plasmatic thrombin/antithrombin } \\
\text { complex } \\
\text { - Elevation of plasma D-dimer } \\
\circ \text { PT, APTT, and fibrinogen > normal range }\end{array}$ \\
\hline Gastrointestinal system & $\begin{array}{l}\text { - Prolonged gastric emptying time } \\
\text { - Vomiting } \\
\text { - Reduced intake } \\
\text { - Dec calcium absorption }\end{array}$ & $\begin{array}{ll}\circ & \text { Nausea } \\
\circ & \text { Vomiting } \\
\circ & \text { Prolonged gastric emptying time }\end{array}$ \\
\hline Endocrine system & - Diabetes mellitus & - Stress hyperglycemia \\
\hline
\end{tabular}

Abbreviations: CKD, chronic kidney disease; SAH, subarachnoid hemorrhage.

be avoided as they are associated with more adverse events, including CIN. ${ }^{8}$ The patients requiring IA contrast are more at risk of CIN than those requiring IV contrast administration. The current guidelines recommend the use of iso-osmolar or low-osmolar contrast in patients with eGFR $<45 \mathrm{~mL} / \mathrm{min}$ for IV route and eGFR $<60 \mathrm{~mL} / \mathrm{min}$ for the intra-arterial route. ${ }^{9}$ In the current case, we used iso-osmolar iodinated contrast. The total volume of contrast used is a significant concern. A volume of greater than $5 \mathrm{~mL} / \mathrm{kg}$ has been found to be a strong predictor of the development of dialysis-dependent nephropathy.$^{10}$ We used a total of $40 \mathrm{~mL}$ of iso-osmolarionidated contrast in three runs in our patient, and the image quality was satisfactory.

\section{Conclusion}

Neurointervention poses a considerable risk in patients with compromised renal functions. We should take all due precautions to prevent further damage to the kidney and avoid a large amount of fluid loading. We suggest periprocedural management of these patients for neurointervention. Renal dialysis should be considered 12 to 24 hours prior to the surgery. The fluid infusions should be minimized to maintain a CVP as close to the baseline as possible. Minimize the use of heparin and, if needed, ACT should be periodically monitored. The use of the lowest concentration of iodinated iso-osmolarcontrast agent, which is sufficient to achieve a satisfactory image quality, is encouraged.

\section{Conflict of Interest}

None declared.

\section{References}

1 Cagnazzo F, Gambacciani C, Morganti R, Perrini P. Intracranial aneurysms in patients with autosomal dominant polycystic kidney disease: prevalence, risk of rupture, and management. A systematic review. Acta Neurochir (Wien) 2017;159(5):811-821 
2 Craig RG, Hunter JM. Recent developments in the perioperative management of adult patients with chronic kidney disease. Br J Anaesth 2008;101(3):296-310

3 Chen S, Li Q, Wu H, Krafft PR, Wang Z, Zhang JH. The harmful effects of subarachnoid hemorrhage on extracerebral organs. BioMed Res Int 2014;2014:858-496

4 Rang ST, West NL, Howard J, Cousins J. Anaesthesia for chronic renal disease and renal transplantation. EAU-EBU Update Ser 2006;4:246-256

5 Rudnick MR, Goldfarb S, Wexler L, et al. Nephrotoxicity of ionic and nonionic contrast media in 1196 patients: a randomized trial. The Iohexol Cooperative Study. Kidney Int 1995;47(1):254-261

6 Katzberg RW, Newhouse JH. Intravenous contrast medium-induced nephrotoxicity: is the medical risk really as great as we have come to believe. ? Radiology 2010;256(1):21-28

7 Mitra R, Rath GP, Dube SK, Hasija N. Anesthetic management in a patient of autosomal dominant polycystic kidney disease with end stage renal disease undergoing endovascular coiling for multiple intracranial aneurysms. J Anaesthesiol Clin Pharmacol 2017;33(2):256-258

8 Aspelin P, Aubry P, Fransson SG, Strasser R, Willenbrock R, Berg KJ; Nephrotoxicity in High-Risk Patients Study of IsoOsmolar and Low-Osmolar Non-Ionic Contrast Media Study Investigators. Nephrotoxic effects in high-risk patients undergoing angiography. N Engl J Med 2003;348(6):491-499

9 Owen RJ, Hiremath S, Myers A, Fraser-Hill M, Barrett BJ. Canadian Association of Radiologists consensus guidelines for the prevention of contrast-induced nephropathy: update 2012. Can Assoc Radiol J 2014;65(2):96-105

10 Freeman RV, O’Donnell M, Share D, et al; Blue Cross-Blue Shield of Michigan Cardiovascular Consortium (BMC2). Nephropathy requiring dialysis after percutaneous coronary intervention and the critical role of an adjusted contrast dose. Am J Cardiol 2002;90(10):1068-1073

\title{
Inherited Factor XII Deficiency-What Is the Real Concern for Neuroanesthesiologist: Bleeding or Clotting
}

\author{
Mouleeswaran Sundaram $^{1}$ Sonia Bansal ${ }^{1}$ Rohini M. Surve ${ }^{1}$ \\ ${ }^{1}$ Department of Neuroanaesthesia and Neurocritical Care, \\ National Institute of Mental Health and Neurosciences, \\ Bengaluru, Karnataka, India

\begin{abstract}
Address for correspondence Sonia Bansal, MD, DNB, PDF, Department of Neuroanesthesia and Neurocritical Care, National Institute of Mental Health and Neurosciences, 3rd Floor, Faculty Block, Neurocentre, Bengaluru 560029, Karnataka, India (e-mail: itz.sonia77@gmail.com).
\end{abstract}

J Neuroanaesthesiol Crit Care 2021;8:210-212.

\begin{abstract}
Keywords

- factor XII

- surgery

- bleeding

- thromboembolism

Factor XII deficiency is a rare disorder that can complicate the perioperative management of a patient. Factor XII plays an important role in the activation of intrinsic pathway of coagulation; the deficiency, therefore, results in prolongation of activated partial thromboplastin time (aPTT). This aPTT prolongation is expected to cause increased bleeding during surgery. However, on the contrary, in vivo isolated factor XII deficiency is associated with increased risk of thromboembolism (this risk being higher than the risk of bleeding). We report the perioperative management of a patient with factor XII deficiency who underwent cervical vertebral fusion $\left(C_{1}-C_{2}\right)$ for atlantoaxial dislocation.
\end{abstract}

published online

June 11,2020
DOI https://doi.org/

10.1055/s-0040-1713559

ISSN 2348-0548. (c) 2020. Indian Society of Neuroanaesthesiology and Critical Care. This is an open access article published by Thieme under the terms of the Creative Commons Attribution-NonDerivative-NonCommercial-License, permitting copying and reproduction so long as the original work is given appropriate credit. Contents may not be used for commercial purposes, or adapted, remixed, transformed or built upon. (https://creativecommons.org/licenses/by-nc-nd/4.0/).

Thieme Medical and Scientific Publishers Pvt. Ltd. A-12, 2nd Floor, Sector 2, Noida-201301 UP, India 